\title{
IoT Based Smart Water Quality Monitoring and Prediction System
}

\author{
Prashant Kamidi, Vamshi Krishna Sabbi, Ramakrishna Sanniti
}

\begin{abstract}
As indicated by Human Rights Watch, twenty million individuals in our nation are as yet drinking water defiled with arsenic. The World wellbeing Organization (WHO) has likewise expressed this emergency as "the biggest mass harming of a populace ever". To diminish the water related ailments and avoid water populace, we need to quantify water parameters, for example, ph, turbidity, conductivity, temperature and so on. Conventional approach of water observing requires gathering information from different sources physically. A while later examples will send lab for testing and breaking down. So as to spare time utilization and diminishing manual exertion my testing supplies will be put in any water source. Thus, this model can distinguish contamination remotely and take essential activities. The primary objective of this paper to assemble a Sensor-based Water Quality Monitoring System. Arduino Mega 2560 go about as a base station and information from sensor hubs will be send to it. For the scholastic reason, this paper exhibits a little model of sensor systems comprising of temperature, water level, stream and ph. At that point ph and temperature sensor esteems were sent cloud stage (ARTIK cloud) and showed as a graphical portrayal on a neighborhood PC. In addition, GSM shield (SIM808) is associated with Arduino Mega which thinks about sensor esteems to edge esteems and sends a text-based notification to the operator if the got esteem is above or underneath the edge esteem. The aftereffects of this undertaking are talked about in the outcome area of the paper. We tried three water tests from three diverse water sources, (for example, modern water, faucet water and pool water). Three water tests gathered from three distinctive swimming pools.(Except one example) $P h$ esteem found in rest of the examples were in typical range (temperature esteem between 26-27'C). Result segment (in page 20) clarifies our venture discoveries in subtleties.
\end{abstract}

Index Terms: Artefacts; Framework; Feature Extraction; Ontology; Query Processing.

\section{INTRODUCTION}

Environment around us consists of five key elements. These are soil, water, climate, natural vegetation and land forms. Among these, waters is the most essential element for human to live. In the 21 st century, providing pure drinking water is becoming a major challenge worldwide. International governing bodies such as United Nations (UN) and World Health Organization (WHO) also recognized human right to sufficient, continuous, safe, and acceptable, physically

Revised Manuscript Received on July 10, 2019.

Prashant Kamidi, Electronics and Communication Department, Godavari Institute of Engineering and Technology, Rajahmundry.

Vamshi Krishna Sabbi, Electronics and Communication Department, Godavari Institute of Engineering and Technology, Rajahmundry

Ramakrishna Sanniti, Electronics and Communication Department, Godavari Institute of Engineering and Technology, Rajahmundry. accessible, and affordable water for personal and domestic use [1]. Impure drinking can cause life threatening disease such diarrhea, cholera, dysentery, typhoid, and polio. The research alarmingly estimates that every year diarrhea alone is causing around death of five lakh people. Figure 1 illustrates how water crisis becoming an epidemic in twenty first century [2]

Now a day's Internet of things is a revolutionary technological phenomenon. It is shaping today's world and is used in different fields for collecting, monitoring and analysis of data from remote locations. Internet of things integrated network if everywhere starting from smart cities, smart power grids, and smart supply chain to smart wearable. Though internet of things is still under applied in the field of environment it has huge potential. It can be applied to detect forest fire and early earthquake, reduce air population, monitor snow level, prevent landslide and avalanche etc. Moreover it can be implemented in the field of water quality monitoring and controlling system. We can design a water quality monitoring system in smart city where there will be a network of devices connected to remote stations and the parameters from the water sources will be stored in a microcontroller via WSN [3]. City dwellers can easily get notified about of the quality of the water via SMS or they can view it on webpage and also local authority can take necessary actions.

In the context of Bangladesh rural area is mostly expose to water pollution. As we can see from figure 2 among all the pollutions in Dhaka city, water pollution is the most contiguous. My motivation for doing this project is to design a prototype which will be feasible and cost effective for poor people. This way we can contribute to my countries development and enrich my knowledge in the field of internet of things. There is no better incentive than saving a children's life and ensure him or her healthier life [4]. 


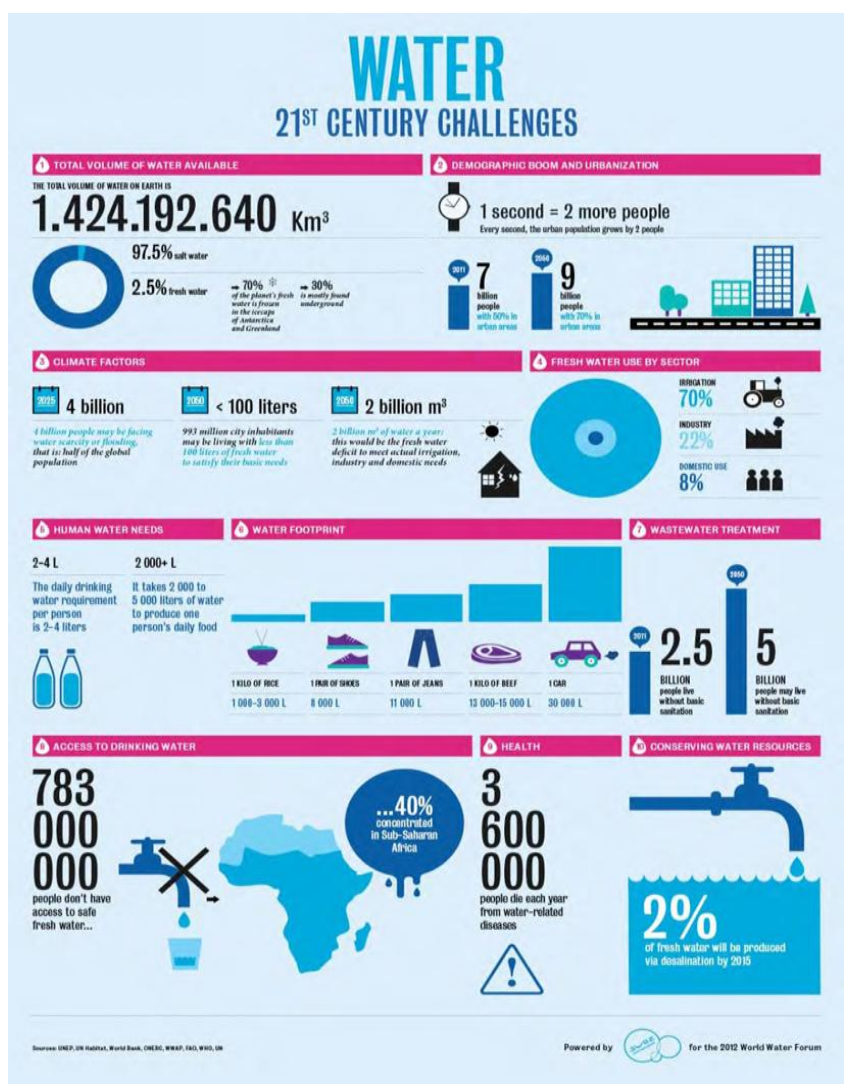

Figure 1: Water 21st Century Challenge (courtesy of World Water Forum)

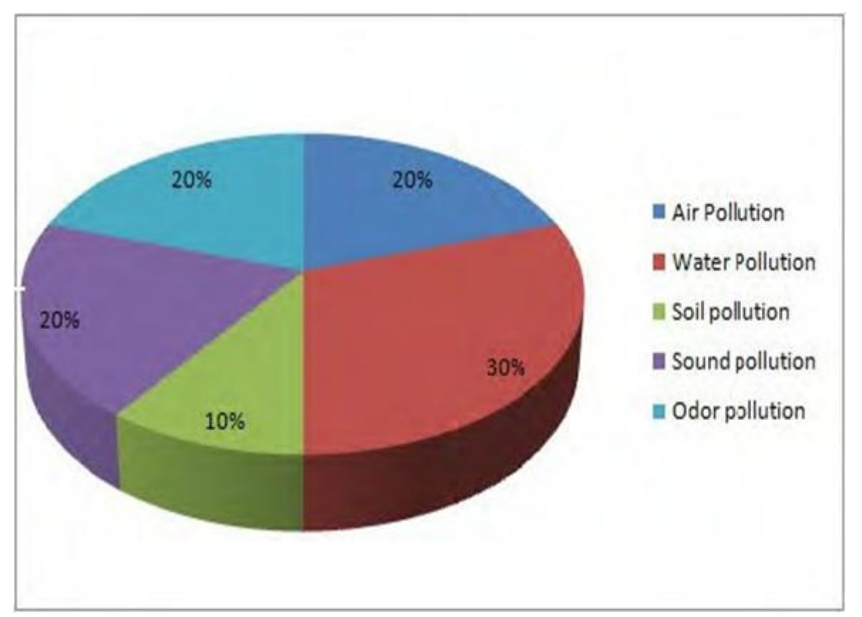

Figure 2: Statistical representation of pollution in Dhaka city (Courtesy of pollutionindhakacity.weebly.com)

The main aim of this paper is to develop a real time internet of things based small scale, cost effective prototype with the help of available sensors. The population of our world is growing rapidly and percentages of drinkable water sources are dropping down very fast. As a result of that meeting the need of ever-growing people, major water sources like rivers, ponds, seas, canals etc. are being filled up and large industrial in fractures are made. According to World Health Organization (WHO) by 2025, half of the world's population will be living in water-stressed areas [5]. For the developing country like Bangladesh, where people cannot afford high cost water purifier this system can provide affordable solution to water crisis.

\section{RELATED WORK}

Water quality monitoring has gained more interest among researchers in this twenty first century. Numerous works are either done or ongoing in this topic focusing various aspects of it. The main theme of all the projects was to develop an efficient, cost effective, real time water quality monitoring system which will integrate wireless sensor network and internet of things. A brief digest of previous works in this field is given bellow.

Kamble, Kakade, Mahajan and Bhosale worked on arduino based mechanized water quality monitoring system based on internet of things. Wang, Ma and Yang (2011) [6] focus on theoretic issues such as routing algorithm, network lifetime, and so on and apply wireless network into online zigbee and GPRS based water monitoring system. Data transmission was done by zigbee protocol and data collected by GPRS shield. MySQL was employed in the database side.

Nasser and Karim [7] proposed model showed us how internet of things platform can be used for water management. Remote Sensing techniques and Internet of things can be applicable for wider spectrum of research domain for monitoring, collecting and analyzing data.

Rao, Marshal, Gubbi, Palaniswami, Sinnott and Pettirogrove [8] in their research, a low-cost wireless sensor network for sensing physical and chemical parameters is proposed. This system observes the behaviors of aquatic animals due to water population using data analysis. Das, Brinda and Jain [9] developed an intelligent system combining remote sensing technology and control applications. In this system they monitored and controlled river and lake water quality. They overcome the technical challenges such as sensor selection and control over wireless network by adopting appropriate algorithm for system design. Wadekar, Vakare and Prajapati [10] in their paper, design a system to limit the usage of water. They set up this system in residential societies and continuously monitor the level of water tank. Home owner will install an android application in his smart phone for getting regular information of water level. The data will be stored on the cloud and if he or she is connected to Wi-Fi then he or she will have access to data. There will be a motor submerge into the tank and according to the level of water and requirement it can be switched on or off.

In this paper, we work on developing an automated IoT based water quality monitoring system. We proposed a model where sensors are connected to Arduino controller. Thus, sensor values are sent to a core micro controller and displayed on a LCD. Arduino is also interface with GSM \& Wi-Fi modules in order to send text notification to user. 


\section{THE PROPOSED MODEL}

We proposed a water quality monitoring system based on internet of things. Water properties can be physical (temperature and turbidity), chemical (ph and dissolved oxygen) and biological (algae and phytoplankton). In the proposed system, physical and chemical properties of water in different water sources such as drinking water, swimming pool water, water bodies inside Dhaka city and industrial waste water are investigated. In this research, we monitor physical and chemical parameters of the aforementioned water sources by using an internet of things-based sensor network. This section composed of two different parts. In first part, a brief overview of the whole system is presented. In the second part, system design will be discussed descriptively. The second part includes both hardware implementation and software.

System architecture: In this project a prototype of water monitoring system is presented. You will get overview of system prototype bellow (Figure.3). A microcontroller is used as a sensor node which stores real time data and sends the data

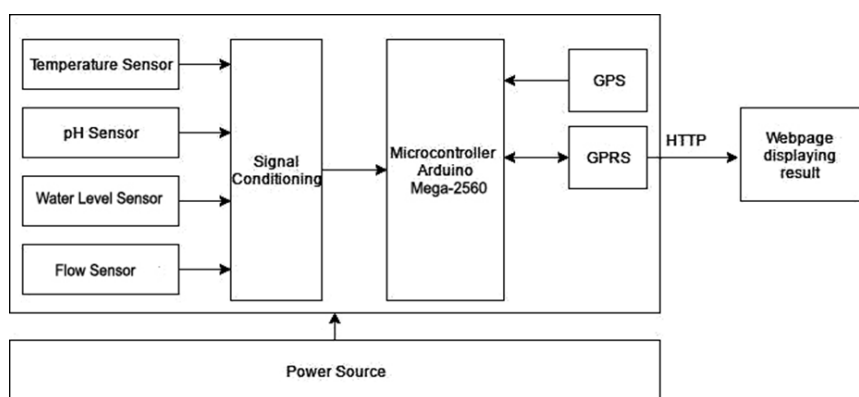

Figure 3: Overview of the system architecture (courtesy of author: Hao Chan, "Water Quality Monitoring System," published on hackster.io)

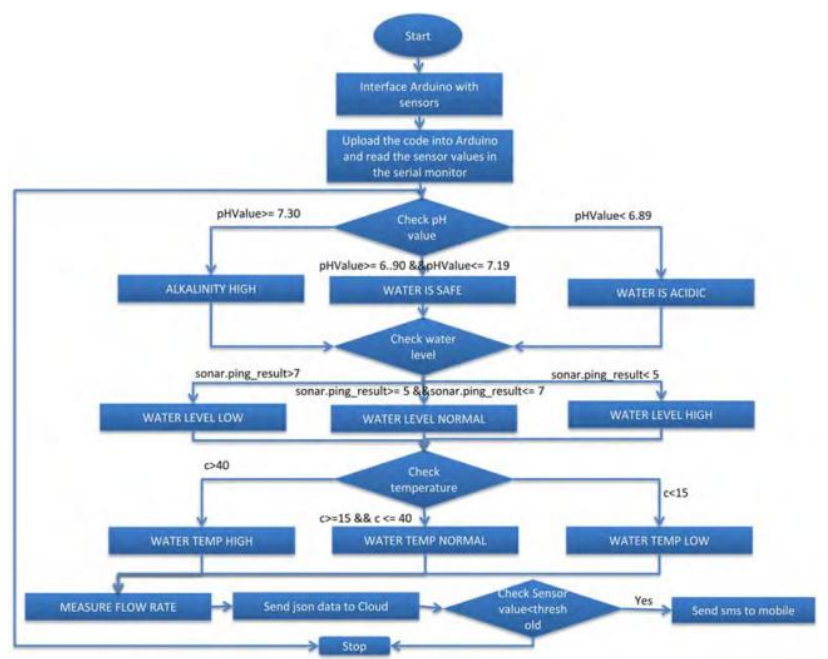

Figure 4: Flow chart of data acquisition process.

\section{A. System Design}

Sensor Node: Arduino is an open-source platform used for building electronics projects. We have chosen mega 2580 over other models (such as UNO) because it provides sufficient digital/analog pin for multi sensor connection. It is microcontroller board based on the ATmega2560. It requires
$5 \mathrm{v}$ power supply and has a clock speed of $16 \mathrm{MHZ}$. We can connect it with computer through universal serial bus (usb) port and can store up to $256 \mathrm{~KB}$ of data. It has 54 digital I/O pins and 16 analog input pins. Four sensors are connected to four digital/analog pin of Arduino. Figure 5 (in the next page) gives us an illustration of Arduino mega [11].

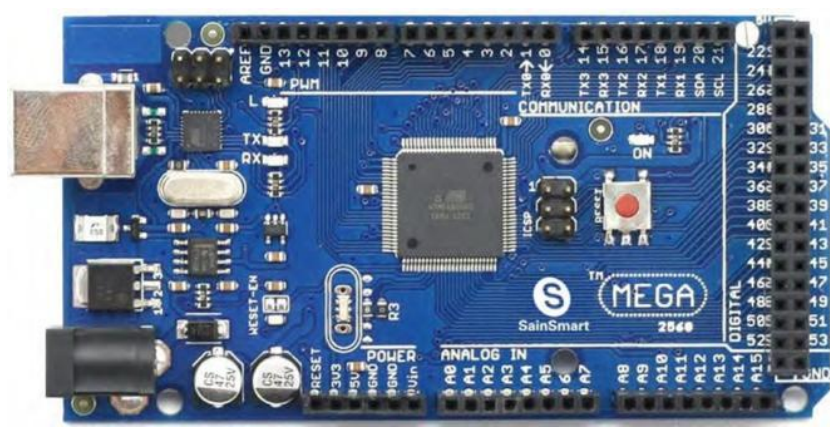

Figure 5: Arduino Mega 2560

LED: In our project we used three different color of LED. Red, green and yellow is used for sensor value high, normal and low respectively for each sensors (expect flow sensor). LEDs have cathode and anode pole which indicates either negative or positive.

Liquid Crystal Display: A $16 \times 2$ liquid crystal display is interface with Arduino mega to display the sensor values on screen. There are two rows and it can display 16 characters per row.

Buzzer: The definition of buzzer is it is an audio signaling device and can be of three types. These three types are mechanical, electromechanical, or piezoelectric. We have used a piezoelectric buzzer in my project. If we apply AC voltage at few kilohertz it will deform. We can deform it back and forth at the same speed as the AC signal and it produces an audible sound. We can apply same process in reserve. Though the buzzer used in this project is ceramic form it can be crystal form too [12].

\section{B. Sensors}

We have used two sensors to measure two parameters of water. These are temperature sensor and $\mathrm{Ph}$ sensor. In addition to that we have also added flow sensor for measuring the water flow of a particular water source and ultrasonic sensors for measuring the water level. Now we will give a brief description of sensors in this subsection. Table 1 gives a summary of sensor specification. is an open-source platform used for [13].

Ph: $\mathrm{Ph}$ is the most important parameter of water. It indicates alkalinity or acidity of a sample. It's an analog sensor manufactured by DF Robot. Though digital meter is much accurate and gives continuous reading, we have to tradeoff between budget of my project and accuracy. $\mathrm{Ph}$ value is measured in the scale of zero to fourteen and temperature value is found between zero to eighty degree Celsius. This model is specially designed for Arduino and comes with a BNC connector, a ph sensor circuit 
board and an analog cable for connection. In order to get correct value we might need to calibrate it (with solution) before testing the sample.

Our target experiment output should be in range of ph 7-8 as we are testing alkaline sample (swimming pool water) [14]. It's a dual-purpose sensor for measuring both temperature and ph value. Temperature sensor is used for measuring water temperature, on the other hand ph sensor for measuring ph value and temperature of surroundings.

Flow: Water flow sensor has a plastic valve body and inside the valve there is a water rotor and a Hall Effect sensor. When water flows through the rotor, rotor rolls. Its speed changes with different rate of flow. The hall-effect sensor outputs the corresponding pulse signal [15]. This model (YF-S201) works in the voltage 5v to 18 and can handle water speed up to $2 \mathrm{mpa}$. In every pulse 450 litters water passes through the valve and the formula for calculating flow rate is: Frequency $(\mathrm{Hz})=7.5 *$ Flow rate $(\mathrm{L} / \mathrm{min})$. Its working flow rate is 1 to 30 litters/per minute.

Level: HC-SR04 is most commonly used sensor for determining distance of an object. Transmitter, receiver and control circuit are three parts of HC-SR04. It has four pins vcc, ground, trigger and echo which connect it to Arduino. Holding this sensor high above the water container will give us raise water from surface. It uses bellow formula to calculate the distance. Maximum threshold distance in the code for this project is $200 \mathrm{CM}$.

Experimental distance $=($ high level time $\times$ velocity of sound (340M/S) / 2.

Temperature: There are different types of temperature sensors available in the market for sensing temperature of any object or surroundings. According to the information of intorobotics there are eleven types of temperature sensors which cover the entire domain of robotics and automations. These sensors vary because of sensor capacity. So choose of a particular temperature for a particular project depends upon its application. Those different types are usually Thermocouple, register temperature detector, thermistors, infrared semiconductors or thermometers. The temperature sensor used in this system is from DF Robot. We have chosen ds18b20 for our project. It's a cheap digital temperature senor which has a one wire interface. It means it only requires pin to communicate with the microcontroller. It is especially suitable for this project because its water proof. Because of its digital output it accurately measures temperature.

Table 1: Summary of Sensor specification used in this system

\begin{tabular}{|c|c|c|c|}
\hline Sensor & Manufacturer & Model & Range \\
\hline $\mathrm{Ph}$ & DF Robot & E-201 & $0-14$ \\
\hline Ultrasonic & Texas Instruments & HC-SR04 & $2 \mathrm{CM}-4 \mathrm{M}$ \\
\hline Turbidity & DF Robot & SEB0189 & $<2 \mathrm{NTU}$ \\
\hline Flow & Unknown & YF-S201 & $1-30 \mathrm{ml} / \mathrm{min}$ \\
\hline Temperature & DF Robot & SEN-00072 & -55 to $125^{\circ} \mathrm{C}$ \\
\hline
\end{tabular}

GSM shield: There are different models of GSM modules available in the market serving different purposes. Few of those are SIM 900, SIM 880C, SIM880L and SIM 808. In this project we will be using latest SIM 808 GSM/GPRS module from SIMCOM which supports quad-band networking.

This module can be easily interface with arduino mega and is controlled by AT command via UART. It requires power supply of $12 \mathrm{~V}$ from an AC100-240V to DC $12 \mathrm{~V} 2 \mathrm{~A}$ power adapter. Figure 6 Illustrates a power adapter.

Software: We wrote our code in arduino integrated development environment (IDE). The source was written in $\mathrm{C}$ and $\mathrm{C}++$ language. It's easy to program and first we tested four of the sensors each individually then integrated the whole system. Figure 4 shows the data acquisition process from sensors. Sensors are interfaced with arduino board. Afterwards we connected arduino through usb cable to an usb port and upload the code. Outputs are shown in the serial monitor of the IDE. Table 2 gives a list of all libraries used for display; data acquisition and cloud data transfer.

Table 2: Libraries in a nutshell.

\begin{tabular}{|l|l|l|}
\hline & Library & Functionality \\
\hline GSM shield & Soft Serial & GPRS/GSM \\
\hline Ultrasonic (HC-SR04) & NewPing & Data Acquisition \\
\hline Ph sensor (E201) & Not required & Data Acquit ion \\
\hline LCD & Liquid Crystal Display & Display \\
\hline Flow sensor (YF-S201) & Not Required & Data Acquisition \\
\hline Ds18b20 & $\begin{array}{l}\text { One Wire and Dallas } \\
\text { Temperature }\end{array}$ & Data Acquisition \\
\hline $\begin{array}{l}\text { Communication } \\
\text { Protocol }\end{array}$ & Arduino Http Client & Cloud Data transfer \\
\hline Data format & Arduino Json & Cloud Data transfer \\
\hline
\end{tabular}

\section{EXPERIMENTS AND RESULTS}

\section{A. Setup}

Figure 6 illustrates a schematic diagram of our system. All the sensors, LCD and GSM shield connected to arduino mega. There is also a buzzer and LED connected to arduino mega. It is required to connect a register in between cathode and anode node of an LED. Otherwise LED will burn. We used 4.7 kilo ohm register for three separate LEDs. There is also 100 kilo ohm register connected in between LCD and arduino. Except D0 to D4 remaining eight pins are connected to arduino mega.

These four pins are for read write purpose we don't require those pins for our purpose.

\section{B. ARTIK Cloud}

ARTIK cloud is an open data exchange for Internet of things. It is interoperable with other devices. It consists of extensive APIs, SDKs, and other tools for building connections between applications, devices, and clouds. 
Now a days this device agnostic and scale able cloud platform is commonly implemented in all internet of things applications, including smart homes, smart cities, and industrial internet of things. Unlike other cloud platform ARTIK cloud platform provides end to end security both in hardware and application level. Because of its developer friendly environment beginner without prior experience in internet of things can get themselves accustomed to it easily.

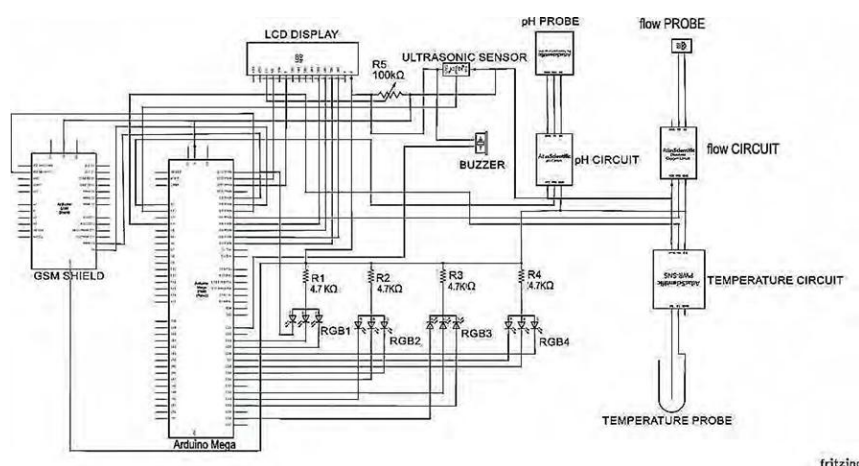

Figure 6: Schematic diagram of the System

Table 3: Summary of sensors interfaced with arduino

\begin{tabular}{|l|l|l|}
\hline Name of the Sensor & Sensor Pin & Arduino Pin \\
\hline SEN 0189 & VCC & 5V \\
\cline { 2 - 3 } & GND & GND \\
\cline { 2 - 3 } & AO & A1 \\
\hline \multirow{5}{*}{ HC-SR04 } & VCC & 5V \\
\cline { 2 - 3 } & GND & GND \\
\cline { 2 - 3 } & Echo & PWM 9 \\
\cline { 2 - 3 } & Trigger & PWM 11 \\
\hline E-201 & PO & AO \\
\cline { 2 - 3 } & GND & GND \\
\cline { 2 - 3 } & VCC & 5V \\
\hline YF-S201 & Yellow & PWM 6 \\
\cline { 2 - 3 } & Black & GND \\
\cline { 2 - 3 } & Red & 5V \\
\hline Ds18b20 & GND & GND \\
\cline { 2 - 3 } & DQ & Digital 2 \\
\cline { 2 - 3 } & VDD & 5V \\
\hline
\end{tabular}

To use this platform developer has to open an ARTIK cloud account. After user log into his account he will be in his own personalize dashboard. In his dashboard he can connect devices to ARTIK Cloud, create Rules, and review, visualize, and export his data in JSON or CSV format. In the dashboard he can create his application and device types and create Manifests for your device types.

We have tested three water samples from three different water sources. Those three samples were swimming pool water, industrial water and normal tap water. If the ph value is above basic (means higher than 7) water is alkane. If it is below 7 the water is acidic. The optimum value for pool water is 7.4. As it is the same as the ph in human eyes and mucous membranes. Low ph value in swimming pool water is harmful for human health because it can cause skin irritation and eye burn if you open your eyes under water. As a result of this low ph value chlorine and other disinfectants won't be as effective as it was for higher value.

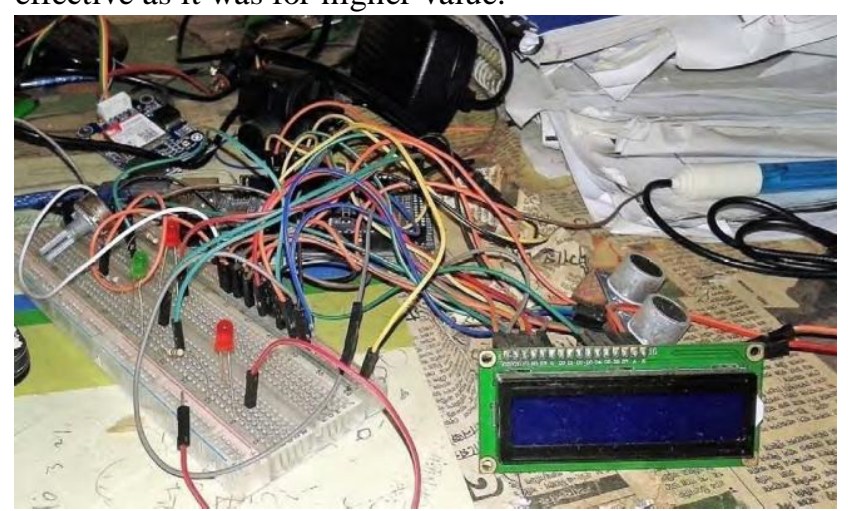

Figure 7: Snapshot of hardware set up for monitoring water quality

So swimming pool will be habitant for micro organs, bacteria's and unsafe for swim. On the other hand, ph value higher than 7.8 can cause coldness in the water and scaling along the sides of someone's pool. Though swimmer might not notice any difference while swimming but the bacteria could be harmful when it comes in touch of your body. So swimming pool water ph range must be kept between 7.2 to 7.8 .

We collected three swimming pool water samples from three different places in-order to make our system full proof. Two of the samples among those three samples gave ph value of $7.3 \&$ 7.1.But the other one gave ph reading of 6.5 which is bellow standard range of ph value in any swimming pool. From the above evidence we came to a conclusion that our system is working expectedly for ph parameter. It is also fair to remark on the water sample of which ph value was low that it not maintained regularly by the concerning authority. Adding substances such as sodium bi-sulphate and sodium bicarbonate for high and low $\mathrm{PH}$ value respectively can stabilize the ph level to normal. Furthermore for recreational pools used for general purpose should not have a temperature higher than 29'C. All three swimming pool samples we tested for temperature gave value between $26-27^{\prime} \mathrm{C}$. We tested multiple times during days and nights in order to find out any abnormal output. Luckily there wasn't any temperature value above maximum range specified.

It is imperative to keep water in right level in swimming pool for healthy pool water filtration system. The water level should be at least one third up the opening of your pool's skimmer. Ideally, though, the water should be level with the half-way point of the skimmer's opening. As our system is not water proof yet, we can't place it to the pool skimmer to measure the water level. Instead of that we place it into ground above water and the value found was $125 \mathrm{CM}$. Waste water released from industries has usually ph in the range of 6.5 to 8.5 before water treatment. Our waste water sample also gave low ph value of 5.5. So it not safe to drink or use in any domestication purpose.

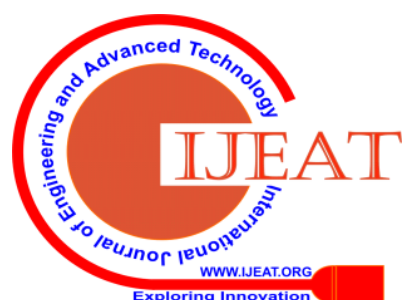


Using flow sensor we can calculate water used in different purposes such as fabricating, processing, washing, diluting, cooling, or transporting a product; incorporating water into a product; or for sanitation needs within the manufacturing facility, optimize water and minimize costs.

If the ph range is in between 6 to 8.5 surface water is impure and drinkable. Normal tap water temperature should be roughly 13 ' $\mathrm{C}$ whether as hot tap water temperature should be around 50 degrees Celsius.

\section{CONCLUSION AND FUTURE WORK}

We have successfully conducted our research and monitored water parameters such as temperature, ph, turbidity. Moreover, we quantified relative value for water level and measure water consumption through flow sensor. Due to limitation of time and budget we focus on measuring quality of water parameters. This project can be extended into efficient water management system of a local area. [Ref: 3] shows how you can control water flow by clicking on or of button on a webpage. A motor will be attached to the water pipe and it will control the water flow from one water carrier to another. This way we can reduce water consumption. Moreover, other parameter which wasn't scope of this project such as turbidity and electronic conductivity can be quantified also. So additional budget is required for further improvement of overall system. We can also work on making a mobile application for remote water monitoring which user can download and install in his or her device and can get real time notification. In future instead of this flow sensor which was used and has the capacity of measuring up to 30 milliliters of water, we could another model which will measure up to 60 milliliters of water accurately.

\section{REFERENCES}

1. Emmanuel ani, "Water Quality Monitoring and Notification System," May 4, 2016.[Online].Available: https://www.hackster.io/eani/water-quality-monitoring-and-notificatio n- system-f85d 23

2. Hao Jei chan, "Water Quality Monitoring System," March 9, 2017. [Online]. Available: https://www.hackster.io/chanhj/water-quality-monitoring-system-ddcb 43

3. M N Barabde, S R Danve, "A Review on Water Quality Monitoring System", In Proceedings of International Journal of VLSI and Embedded Systems-IJVES, Vol 06, Article 03543; March 2015, pp. 1475-1479.

4. S.Silva, N. Hoang Nghia, V. Tiporlini, and k.Alameh, "Web based water quality monitoring with sensor network: Employing zigbee and wimax technologies," in High Capacity Optical Networks and Enabling technologies (HONET). IEEE, 2011, pp. $138-142$.

5. A.S. Rao, D.Izadi, R.F Tellis, S.W Ekanayake, and P.N. Pathairana “ Data monitoring sensor network for biggest research testbed," in 2009 5th International Conference on Intelligent Sensors, Sensor Networks and Information Processing (ISSNIP). New York, USA: IEEE, 2009. pp. 169- 173 .

6. Wang X, Ma L and Yang H,'Online Water Monitoring System Based on ZigBee and GPRS," In Proceedings of Procedia Engineering. ScienceDirect, 2011, 2680-2684.

7. Nasser, N., Ali, A., Karim, L., \& Belhaouari, S. (2013). An efficient Wireless Sensor Network- based water quality monitoring system. In 2013 ACS inter-national conference on computer systems and applications (AICCSA) (pp.1-4).

8. Rao, A.S., Marshall, S., Gubbi, J., Palaniswami, M., Sinnott, R.O., \& Pettigrovet, V. (2013). Design of low-cost autonomous water quality monitoring system. 2013 International Conference on Advances in Computing, Communications and Informatics (ICACCI), 14-19.

9. Das, Brinda and P. C. Jain. "Real-time water quality monitoring system using Internet of Things." 2017 International Conference on Computer, Communications and Electronics (Comptelix) (2017): 78-82.

10. S.Wadekar, V.Vakare, R.Prajapati, Shivam Yadav and V.Yadav," Smart Water Management using IOT,'In Proceedings of 5th International conference on Wireless Networks and embedded System (WECON),2016.

11. M. Zennaro, A. Floros, G. Dogan, S.Tao, C.Zhichao, H. Chen, M. Bahader, H. Ntareme, and A.Bagula, "On the design of a water quality wireless sensor network (wqwsn) : An application to water quality monitoring in Malawi," in International Conference on Parallel Processing Workshops (ICPPW '09). IEEE.

12. Cloete N.A, Malekain R and Nair L "Design of Smart Sensors for Real-Time Water Quality Monitoring” In Proceedings of IEEE Access. IEEE, 16 July 2016, page. 33975 - 3990.

13. ARTIK Cloud Developer," ARTIK Cloud - via Arduino" [online]available:https://developer.artik.io/documentation/advanced-co ncepts/mqtt/color-mqtt- arduino.html.

14. Keshtgari, M. (2012). A wireless sensor network solution for precision agriculture based on zigbee technology. Wireless Sensor Network, 4(1), 25-30.

15. N. Chaamwe, "Wireless sensor networks for water quality monitoring A case of Zambia ," in 2010 4th International Conference on Bioinformatics and Biomedical Engineering (icBBE). EEE, 2010, pp $1-6$. 